\title{
Morality matters? Consumer identification with celebrity endorsers in China
}

\section{Felix Martin and Fu Tao-Peng}

\begin{abstract}
Identification as a source of ethical attitudes is traditionally associated with Western rather than Confucian cultures. Here, two empirical studies examine the impact of celebrity endorsement on purchase intention among consumers of Chinese origin, through processes of consumer identification with celebrity moral traits. In this way, this paper develops the literature on ethics amongst consumers of Chinese origin and, more generally, the literature on source credibility through moral traits. It is also one of the first papers to consider the moral consumption habits of online gamers.
\end{abstract}

Key Words: Celebrity endorser, moral character, ethical marketing, online-game ethics, moral identification, cultural moral values. 


\section{Introduction}

"The Olympic swimming star Michael Phelps, who was photographed inhaling from a marijuana pipe, has lost a major sponsorship deal and has been suspended from competition for three months. Kellogg, a U.S. food company, said Thursday that it would not renew its contract with Phelps when their deal expires at the end of February... 'Michael's most recent behaviour is not consistent with the image of Kellogg', Susanne Norwitz, a spokesman for the company, said in a statement." (New York Times, 2009)

This paper extends the literature on source credibility (Liu, Huang, and Minghua 2007) by focusing on the moral traits of celebrity endorsers. Consumers of Chinese origin were asked to cast a moral judgement on a celebrity endorser's moral traits and then to state whether they identify with that celebrity. This follows the logic of moral judgement, comprising cognitive and conative elements: "moral judgement is much like aesthetic judgement: we see an action or hear a story and we have an instant feeling of approval or disapproval" (Greene and Haidt 2002, 517). The study focuses on celebrities that are not typically associated with moral character, but are highly sought after by firms as endorsers of their products, such as young pop stars (Justin Bieber) and online gamers ('Faker', a celebrity in the League of Legends online game). This gives our study managerial relevance and differentiates it from those that consider the influence of the consumer's moral identity (Aquino and Reed 2002) on consumers' attitudes and behaviours. Even though a consumer's moral identity is involved in the casting of moral judgements, this study focuses on the mechanism of identification that mediates the relationship between celebrity endorser and purchase intention. 
The effectiveness of celebrity endorsement is closely bound up with the extent to which it reflects the values and ideas of a given culture, so that its impact will vary from culture to culture (Choi, Lee, and Kim, 2005). China is characterised by collectivist cultural values (Hung and Li 2007) as well as risk aversion and high power-distance (De Mooij 2005). Confucian morality requires individuals to demonstrate certain personal qualities in addition to adherence to the five cardinal virtues of benevolence, filial conduct, trustworthiness, loyalty and righteousness (Tan and Snell 2002). The interpretation of these behaviours takes place within relationally-defined norms exercised within interpersonal ties, or guanxi (Gu, Hung, and Tse 2008). Guanxi has been called the glue that binds Chinese society together (Lovett, Simmons, and Kali 1999). The importance of the role and the level of intimacy that defines these ties demands reflexivity and ingenuity in determining the appropriate moral behaviour between members of a guanxi association, affording Chinese morality considerable latitude (Tan and Snell 2002). This is quite different from the typical Western approach to morality, whereby people choose whether or not to act according to empathy and autonomous moral judgement based on an ideal type as a source of identification (Gilligan 1982). Identification captures the extent to which one party "adopts behaviors derived from another person or group because this behavior is associated with a satisfying self-defining relationship to this person or group" (Kelman 1961, 63). It follows that the importance of identification with moral traits as a source of purchase intentions may be expected to be greater among Western consumers (e.g., Johnson 2005) than among consumers of Chinese origin. By contrast, the normative value of moral traits (e.g., credibility) is likely to be more important amongst consumers of Chinese origin.

However, China and many other parts of Asia are undergoing profound changes through which people, especially the young, are embracing Western values (Arora 2005; Stanat 
2006). Tan and Snell (2002) found that in Singapore guanxi-linked morality played only a minor role in moral reasoning and was largely overshadowed by Western-style morality. This makes the study of ethics amongst consumers of Chinese origin especially relevant, yet such studies are a relatively recent development (Moon and Shen 2010; Zu and Song 2009). For example, research has found that consumers of Chinese origin are concerned with environmental and social issues (Chung, Eichenseher, and Taniguchi 2008) and willing to act in line with these concerns (e.g., Chu and Lin 2012). In the marketing context, such studies are also important for practical reasons, since, as Chan (2008) notes, in China $40 \%$ of youthproduct advertising features at least one celebrity, making the effect of this tactic on young people particularly critical for advertisers in China. By addressing the influence of moral traits on the celebrity endorsement of products typically associated with younger consumers of Chinese origin, this research hopes to advance the understanding of ethical attitudes amongst such respondents and to provide managerial implications for advertising professionals.

The focus on online gamers also gives this paper unique relevance. Very little is known about the moral consumption habits of online gamers, even though the development of the internet and game-development technology has turned successful online gamers into worldwide celebrities. According to the League of Legends official statistics, there are 67 million players of this game alone, accounting for $1 \%$ of the world's population in 2014 (Highscalability 2014). As a result, online game advertising is becoming increasingly popular, and the use of game celebrities for advertising has also increased (Cuneo 2004; ESPN 2015). For all their popularity, online games have attracted considerable controversy amongst educational researchers. Playing games displaces the time that players might spend on other activities, potentially resulting in lower academic performance (Chan and Rabinowitz 
2006; Sharif and Sargent 2006), gaming addiction (Gentile 2009, 2011), impulsiveness and lower attention to other matters (Hastings et al. 2009). Research has shown that playing violent online games can increase aggressive cognitions, affects and behaviours both in immediate and long-term contexts (e.g., Anderson and Dill 2000; Anderson, Gentile and Buckley 2007; Anderson et al. 2010). It can also result in desensitization to violence (Bartholow, Bushman, and Sestir 2005), diminished empathy, and a lower likelihood of prosocial behaviour (Bushman and Anderson 2009). On the other hand, pro-social online games can have the opposite effect, increasing cooperation, sharing, empathy, and helping behavior in adolescents (Gentile et al. 2013), and pro-social behavior among children (Sestir and Bartholow 2010). League of Legends has both violent and pro-social (e.g., collaboration amongst team members) components and Faker is widely acknowledged as the public face of the game. By targeting this consumer group, this study also contributes to the understanding of ethical consumption among communities of online gamers.

\section{Theoretical Propositions}

McCracken $(1989,310)$ defines a celebrity endorser as "any individual who enjoys public recognition and who uses this recognition on behalf of a consumer good by appearing with it in an advertisement". Celebrity endorsement is considered an effective marketing approach and has become ubiquitous in the market place all over the world (Spry, Pappu, and Cornwell 2009). Celebrity endorsers help brand recognition and recall (Friedman and Friedman 1979), leading to positive product evaluation and advertising ratings (Dean and Biswas 2001) and purchase intention (Lafferty, Goldsmith, and Newell 2002; Tripp, Jensen, and Carlson 1994). McCracken (1989) suggests that using celebrities as product endorsers is 
more efficacious than using unknown actors or models, because they are present as active personas in the minds of consumers, conveying a vivid message. Thwaites et al. (2012) point out that celebrities attract attention and thus can be particularly effective in various situations such as new-brand introduction and brand-image switching, especially when consumers have low involvement with the product category or are time-constrained to make purchase decisions. Celebrities including movie stars, singers, and athletes are frequently seen in various types of advertisements and some even endorse multiple products (Tripp, Jensen, and Carlson 1994). Products being endorsed are not limited to physical goods, but also include services and ideas (Pornpitakpan 2008).

Several models have been proposed by researchers to explain the phenomenon by which celebrity-endorser image is transferred to associated products (Liu, Huang, and Minghua 2007; Louie and Obermiller 2002). Meaning Transfer Theory suggests that consumers' attitudes about a celebrity transfer to the endorsed brand by recurring association (McCracken 1989; Langmeyer and Walker 1991). Silvera and Austad (2004) note that positive associations with the celebrity transfer to the endorsed brand upon consumers' exposure to multiple celebrity-brand pairings. The match-up hypotheses suggests that consumers seek congruity between celebrity endorser and endorsed brand (Misra and Beatty 1990; Till, Stanley, and Busler 2000). Thus, the celebrity endorser will be more effective when consumers find better fit between endorser and product (Liu, Huang, and Minghua 2007; Lohneiss and Hill 2014). It follows that retailers need to evaluate a celebrity endorser's personal traits before associating their brand name with that celebrity (White, Goddard, and Wilbur 2009). Advertisers can frame the association between celebrity and product to enhance its strength and focus on the best aspect of the celebrity for the product (Till, Stanley, and Priluck 2008). Silvera and Austad (2004) argue that 
consumers also pay considerable attention to whether celebrity endorsers truly like the product they endorse; the logic behind this is that consumers will value the product less when they consider the celebrity is motivated by the endorsement fees they receive rather than the product itself.

Another reason why celebrities are particularly effective is because of characteristics such as physical features (e.g., attractiveness), attitudes, beliefs, behaviours and demographics (e.g., profession) (Erdogan 1999; Misra and Beatty 1990; Pornpitakpan 2008). These elements were extensively applied in celebrity literature as the component of source credibility (Liu, Huang, and Minghua 2007) and can be extended to include moral traits (Mishra, Subhadip, and Ainsworth 2015). Links between nodes in a consumer's memory (Keller 1993) enable the transfer of celebrity attributes and their symbolic associations to an endorsed brand (McCracken 1989), promoting self/brand congruence, with positive outcomes for brand evaluation (Dwivedi, McDonald and Johnson, 2014; Dean and Biswas 2001) and purchase intention (Lafferty, Goldsmith, and Newell 2002; Tripp, Jensen, and Carlson 1994). This is facilitated by the fact that brands are perceived as having human characteristics (Aaker 1997; Lee and Cho 2009). By contrast, negative information about a celebrity endorser downgrades their credibility, leading to poorer attitudes toward the brand (Zhou and Whitla 2013). The logic is consistent with the findings from Till and Shimp (1998) that low evaluation of a celebrity endorser results in low assessment of the endorsed brand, reducing purchase intention. With regard to moral associations, Louie, Kulik, and Jacobsen (2001) found that the level of culpability in a transgression by a celebrity endorser will negatively influence the stock price of the endorsed company. In general, celebrityendorser moral traits can act as a source of meaning transfer and credibility that renders the product more attractive, increasing purchase intention. 
It is proposed that:

H1: Celebrity-endorser moral traits increase purchase intention of the endorsed product.

Erikson (1964) argues that people tend to seek a balance between their moral self and their behaviour, which also implies that one's moral identity is an essential element of the individual. When customers perceive the moral traits of a celebrity endorser, it is reasonable for them to process the message through their moral sense and to identify with the celebrity endorser to reinforce their own moral identity. In this way, celebrities shape the consumers' self-concept (Dwivedi, McDonald, and Johnson 2014). On the other hand, when consumers feel that their moral identity is being compromised, or find it inconsistent with the celebrity-brand characteristics, they are more likely to develop a negative attitude toward the endorsed brand and dis-identify with it. Johnson (2005) found that consumers develop a sense of identification and intimacy with a celebrity after being exposed over time to his/her news in the media. According to Horton and Wohl (1956), this one-sided nature of connection and the illusion of interacting with the celebrity face-to-face can be described as a para-social relationship. When people develop a strong para-social relationship, they tend to fantasise a relationship with the celebrity, reflecting a deep level of identification that can result in attitudinal and behavioural changes (Hung, Chan, and Tse 2011). The celebrity endorser will be perceived as a pleasant companion who can help with selfexpression (Kim, Han, and Park 2001; Thomson 2006). Consumers with higher levels of identification will accordingly show more favourable attitudes towards a celebrity endorser (Johnson 2005), resulting in attachment and loyalty towards the endorsed brand (Kim, Han, and Park 2001). Aquino et al. (2009) note that moral identification exercises a stronger influence on processes that guide one's cognition and behaviour compared with other forms 
of identification. Thus, celebrity-endorser moral traits will increase the identification of the consumer with the celebrity endorser.

It is proposed that:

H2: Celebrity-endorser moral traits increase consumer identification with the celebrity endorser.

Research on consumer ethics presents a fragmented picture. Carrigan and Attalla (2001) proposed that consumers' attitudes to ethical purchasing is not simply divided into yes-orno, but into four distinct categories - caring and ethical, cynical and disinterested, confused and uncertain, and oblivious. Creyer and Ross (1997) noted that consumers will purchase goods from unethical firms if the price is cheaper. Yet Aquino and Reed (2002) argue that moral identity can be organised around traits associated with moral behaviour and that individuals are driven to act in a way that is consistent with their moral traits. According to self-verification theory, giving an accurate portrayal of oneself to others is a basic need of every individual, as it assists his or her psychological coherence (Winterich, Mittal, and Aquino 2013). Celebrities serve a vital value-expressive function that is typically associated with reference groups (Bearden and Etzel 1982; Escalas 2004). For this reason, celebrity endorsements tend to adopt value-expressive appeals (Johar and Sirgy 1991) that can become self-definitional for the consumer (Dwivedi, McDonald, and Johnson 2014), and thus favour moral attributions. It follows that moral traits may be a viable explanation for the effectiveness of celebrity endorsers in driving purchase intention, as consumers transfer the moral traits of the celebrity endorser to the endorsed brands and manifest their moral identity through the purchase of such brands. This idea derives further support from the fact that "people tend to prefer things that are similar to themselves to boost their selfesteem and self- evaluations" (Choi and Winterich 2013, 98). It also helps explain why 
negative publicity about a celebrity endorser tends to be more influential than positive news reports (Louie, Kulik, and Jacobsen 2001). When it matters, lack of ethics can have very negative consequences for a firm, especially given the potential for negative word-of-mouth in social media (Thwaites et al., 2012). Therefore, it is proposed that the more the consumer identifies with the celebrity endorser's moral traits, the higher the willingness to purchase the endorsed product.

It follows that:

H3: Consumer identification with celebrity-endorser moral traits increases purchase intention of the endorsed products.

Finally, it is hypothesised that:

H4: Consumer identification with celebrity-endorser moral traits mediates the association between celebrity-endorser moral traits and purchase intention.

The hypothesized relationships, without the mediation hypothesis included in the model $(\mathrm{H} 4)$, are presented in Figure 1:

\section{Insert Fig. 1 about here}

\section{Method}

To test the impact of perceived celebrity-brand moral traits on purchase intention, it was essential that respondents should be familiar with the celebrity. Two methods for the selection of a celebrity were initially considered. The first was to construct an artificial scenario describing a celebrity. This proved too difficult, given the complexity of celebrityendorsers' lives, and was soon abandoned. Besides, Money, Shimp and Sakano (2006) argue 
that using an actual celebrity in a study is preferable to a fictional one, as it provides a sense of realism in investigating the effects under consideration. A second method was tested with sixty respondents. They were presented with a product (Adidas shoes) and asked to think of the celebrity endorser. Most of the respondents could not think of the celebrityendorser association without prompting.

Accordingly, it was decided to pre-select the celebrity endorser, according to three criteria: a) high likelihood of recognition by the target group; b) high likelihood that his or her moral character should be known to the target group, and c) a recent ethical controversy surrounding the celebrity endorser, as this would make their moral character more salient to respondents. The two MSc students charged with collecting the data considered several possible celebrity endorsers in conversation with friends at their university and elsewhere, and made their final choice as follows:

\section{Study 1: Justin Bieber}

Study 1 adopted Justin Bieber as the celebrity endorser. Bieber is a pop singer, dancer and actor whose songs are largely focused on teenage romance and who entered the world of celebrity as a young boy. The survey was conducted soon after a period of massive media publicity showing his involvement in drink-driving. Yet even after Bieber was arrested for this offence, Adidas did not cancel their contract with him and claimed that "nothing is changing in our relationship with Mr. Bieber at this time" (TMZ 2014). Bieber has mass recognition all over the world (including among consumers of Chinese origin) and given his recent misbehaviour seemed ideally placed to test the impact of celebrity-endorser moral traits on purchase intention among young consumers of Chinese origin. 


\section{Study 2: Faker}

Study 2 concerned Faker (Lee Sang-hyeok), a professional champion in the League of Legends online game. League of Legends is an example of networked game-play, whereby players adopt a character and interact with other players on the internet, lending the game a social dimension (Pham 2003).

The origins of the digital-games industry can be traced back to the early 1950 s. However, since the 1990s the development of the internet and game-development technology have led to massive increases in the number of people playing computer games, giving players like Faker celebrity status. Because of the widespread use of online games, the world-wide match finals of games like League of Legends and DOTA attract audiences exceeding 100 million people. Since online gaming has a controversial ethical image and League of Legends has a large following amongst consumers of Chinese origin, Faker was also considered ideally placed to test the relationship between celebrity moral traits and purchase intention among young consumers of Chinese origin.

\section{Questionnaire collection}

Questionnaires for the two studies were collected through snowballing online sampling, starting with acquaintances of the students. Online survey has become a prime survey vehicle due to its convenience, verifiability, low-cost delivery and return systems, as well as easy access and feedback mechanisms (Kaye and Johnson 1999). Moreover, according to Malhotra and Birks (2007), respondents are allowed to complete the survey wherever and whenever they want, which encourages better completion. The online questionnaires were 
developed using Qualtrics. They were drafted in English and translated into Chinese, and made available in both languages. The Bieber questionnaire was distributed through various social-media platforms. For the Faker questionnaire, however, all respondents were recruited through a League of Legends network, of which the student was a member. All the respondents to both questionnaires were of Chinese origin (Mainland China and Taiwan), mostly aged in their twenties. The first study included 171 respondents aged $18-41(90 \%, 18-$ 30), $55 \%$ of whom were female and $45 \%$ male. The second study included 90 respondents aged $18-30,83 \%$ of whom were male and $17 \%$ female; these figures are broadly in line with the profile of the typical League of Legends player (IGN 2015).

\section{Scales}

All items in the questionnaires were measured on a five-point Likert scale. Thomson (2006) notes that today's consumers recognise celebrities as brands, as they are professionally managed, can be licensed, and have the associations and features of a brand. As noted earlier, brands are personalised and endorsers transfer their own personality traits to the brand. Accordingly, 'celebrity-endorser moral traits' (MT) was measured through a personality-brand measure derived from Davies et al. (2004), comprising the following items: honest, sincere, trustworthy, socially responsible. Respondents were asked to score the celebrity on those traits in answer to the prompt 'I think [celebrity] is...' (Study 1: $\alpha=0.927 ; M=2.069 ; S D=0.93 ;$ Study $2: \alpha=0.883 ; M=3.396 ; S D=1.0504)$. The measure of 'identification' (ID) was taken from Aquino and Reed (2002) and included seven items, such as 'It would make me feel good to be a person like [Celebrity]' (Study 1: $\alpha=0.918 ; M=1.965$; $S D=0.88 ;$ Study 2: $\alpha=0.814 ; M=2.86 ; S D=0.8381)$. 'Purchase intention' (PI) was measured 
through a scale derived from Ohanian (1991), e.g. 'I would consider a product endorsed by the Celebrity to be my first choice for future purchases' (Study 1: $\alpha=0.933 ; M=1.858$; $S D=0.88 ;$ Study 2: $\alpha=0.706 ; M=3.10 ; S D=0.898)$.

\subsection{Results}

\subsubsection{Study 1}

As can be seen from Table 1, the correlations between MT, ID and PI are strong and in the hypothesised direction.

\section{Insert Table 1 about here}

To test our main hypotheses $(\mathrm{H} 1-\mathrm{H} 3)$ and mediation effect $(\mathrm{H} 4)$, a simple regression was first drawn for the direct effect of MT on PI $(b=.764, t=-15.78, p<.001)$, supporting $\mathrm{H} 1$; in other words, when the celebrity endorser is perceived to have a moral identity, purchase intention of the endorsed product increases. To test for an indirect effect of MT on PI through ID (H2-H4), we built a structural-equation model using AMOS with 2000 bootstrap samples, following the recommendations of MacKinnon (2008) and Shrout and Bolger (2002). The result is a well-fitting model $(\chi 2=42.74, \mathrm{df}=38$; $\mathrm{RMSEA}=.061, \mathrm{CFI}=.982, \mathrm{TLI}=.977)$. An analysis of the indirect-effect matrix shows that the mediated effect MT-ID-PI is significant ( $p<.001)$ (supporting $H 4)$, whilst the direct effect is still sign, but at a lower significance level $(p<0.028)$ than in the regression, suggesting partial mediation in support of H4. In other words, the effect of MT on PI is partly explained through identification of the consumer with the celebrity. 


\subsubsection{Study 2}

Table 1 also contains the correlation matrix for the measurement variables in Study 2. Since $\mathrm{PI}$ is not significantly correlated with MT and ID, Study 2 only supports $\mathrm{H} 2(b=.596, p<.001)$ and no coefficients for Study 2 are included in Table 2. In other words, gamers recognise moral traits in Faker and identify with them, but this does not influence their purchase intention towards the endorsed products.

\section{Insert Table 2 about here}

\subsection{Discussion}

This paper set out to study whether the moral character of a celebrity endorser influences the purchase intention of endorsed products in respondents of Chinese origin. The two studies offer contradictory answers, pointing to the peculiarities of the online-gaming context as the differentiating factor.

Study 1 shows that Bieber's moral traits are a source of moral credibility and identification for consumption. It was argued earlier that Western cultural values favoured identification with moral traits, whilst Confucian values tended towards normative adherence. Recent studies have claimed that consumer attitudes among young Chinese consumers are shifting in line with Western values. The findings of Study 1 can be interpreted as offering indirect support for this claim, as they show that identification is an important driver of purchase intentions among such consumers. However, the crosssectional nature of the study, the limited information about the respondents' demographics and the incipient theoretical development of the relationship between values and moral behaviour reduce the reliability of such interpretation. At the very least, the findings show 
that identification with moral traits can be an important conduit to promote ethical consumption among young consumers of Chinese origin. Identification turns celebrities into forms of self-expression, increasing positive attitudes towards ethical brands beyond the effect of source credibility. This offers increased opportunities for ethical firms to develop strong bonds with consumers that can deliver increased purchase intention. However, identification with a celebrity also increases moral hazard for the firm when the celebrity fails to conform to the ideal that consumers hold of him or her. Processes of disidentification can result in stronger negative attitudes and behaviours towards the brand, such as negative word-of-mouth, than would result from normative influences. The managerial implications of this for firms using Bieber as endorser are discussed below.

Study 2 shows that gamers recognise moral traits in Faker and identify with them. Moral traits are implicit in the pro-social aspects of the game, such as the emphasis on team dynamics, which demands a high level of trust amongst players. Yet the findings show that these traits do not influence gamers' purchase intentions. A possible explanation is that moral dimension forms only a small part of the art of winning games, as a means to an overall amoral end. Whilst gamers acknowledge Faker as moral and think of themselves in the same way, it is his overall amoral image as a winner of violent games that becomes salient for guiding cognitions and behaviours. The influence of this image extends, through mental associations, to products endorsed by Faker. The fact that Faker personally sponsors only products associated with Riot Games (maker of League of Legends) reinforces this argument. This interpretation derives support from the association of frequent exposure to violent video games with amoral behavioural outcomes. 
Future studies should test this further by comparing the effect of moral traits and amoral traits of celebrity endorser on purchase intentions. The conclusions of such studies could have implications for the study of moral development (Kohlberg 1971) among gamers, especially adolescents, since action (i.e. playing the games and purchasing items related to the games) can have a reinforcing or weakening effect on moral identity (Blasi 1984). The findings reduce the moral hazard to the firm of targeting gamers with celebrity endorsers, since gamers' purchase intentions will be tolerant of the celebrity endorser's moral misbehaviour. This is further discussed below.

\subsection{Managerial Implications}

The findings suggest that the impact of celebrity-endorser moral traits on purchase intention among respondents of Chinese origin is context-dependent. This ambiguity supports the so-called 'myth of the ethical consumer' (Eckhardt, Belk, and Devinney 2010), which calls into question the extent to which marketing ethics and social responsibility have implications for consumption. The moral traits of the celebrity endorser matter in some cases, but not in others. Where they matter, they become a source of identification with attitudinal and behavioural impacts that can deliver competitive advantage in the marketplace. Thus, firms must develop a clear understanding of the ethical dimension and the brand, and the moral position of their celebrity endorser vis-à-vis consumers, to maximise the benefits of ethical identification. However, they must also understand the risks involved in this strategy.

The findings suggest that Bieber ought to sponsor products with moral-trait associations such as 'trustworthy', 'socially responsible' or 'honest'. Mainstream consumer brands like 
Adidas and Alibaba broadly fit this definition. However, if the consumer feels that their moral identity is compromised, the para-social relationship that makes Bieber a trusted companion will be eroded, with implications for the brand. An example emerged when Bieber was caught driving when drunk, yet Adidas refused to break its contract with Bieber at that time. The reason may be that consumers tend to seek excuses for celebrities with whom they identify (Johnson 2005), especially when the misbehaviour is not excessive, the celebrity is deemed to be not fully responsible for their behaviour (Louie, Kulik, and Jacobsen 2001), or (in the most extreme case) the information does not reflect badly on the consumer (White, Goddard, and Wilbur 2009). Consumers may also opt to focus during the time of misbehaviour on other aspects of the celebrity endorser's image that matter to them, such as their professional performance (Bednall and Collings 2000; Miller and Laczniak 2011). Bieber's drunk-driving was in line with the behaviour of other pop stars and was explained away by the media as a rite of passage into adulthood (The Star 2014). Overall, Adidas must have thought that Bieber's actions would not undermine his moral image, given the nature of the misbehaviour and the degree of consumer identification with him.

Adidas' attitude towards Bieber contrasts with that of Kellogg's towards Michael Phelps after he was allegedly caught smoking marijuana. Phelps' misbehaviour was directly contrary to the model sportsman he was meant to embody. More importantly, the level of consumer identification with him was probably limited, reducing their tolerance and increasing the moral hazard for the firm. It is interesting that Adidas continues to sponsor Bieber, even though he has recently endorsed sweepstakes offered by Ubisoft (creator of Assassin's Creed, a violent video-game). Whether this endorsement is considered too indirect or weak to spoil Adidas' moral image, or whether Adidas is changing (reaching out 
to rapper gangs, for example) alongside Bieber himself is a question for further studies to consider. In that case, Adidas would have to assess carefully the risk of losing its mainstream 'moral' audience in the attempt to reach new audiences, such as those associated with rapper gangs.

Following this discussion, Faker would represent a low moral hazard for firms where the sponsorship is aimed at the community of League of Legends players, since celebrityendorser moral identity does not impact on the consumption habits of such players. This is the case with Korean Telecom's sponsorship of Faker's League of Legends team. The same could not be said if Faker were to endorse products aimed at a general audience. Using Faker for that purpose would require a careful analysis of the moral perception of the League of Legends game amongst non-players.

It follows that consideration of the practical importance of an endorser's moral traits for brand evaluation and purchase intention must take account of a) the degree of consumer tolerance, based on dynamics of identification with the celebrity endorser, and b) a contextual interpretation of industry characteristics. The findings suggest that the origin of the celebrity does not impact on identification; yet cultural conditioning may impact on the level of tolerance of celebrity-endorser misbehaviour. In this sense, what is excessive behaviour, or what reflects badly on the consumer, would be influenced by ethical norms prevailing in the consumer culture. Thus, the decisions of Chinese consumers may be more influenced by social norms than those of Western consumers. Anecdotal evidence is provided by derogatory comments made by young Chinese Bieber fans about Bieber's tattoos, and the fact that "he was a bit lazy on The Great Wall" (Vice.com, 2013). Such impact from cultural influences on tolerance will in turn increase the moral hazard of using 
celebrity endorsers in industries where moral identity is a factor influencing brand evaluation and purchase intention, and calls for active management of the moral image of the celebrity endorser.

Innovative firms wishing to appoint Western celebrities to market to Asian consumers would be well advised to undertake market research about the perception of the celebrity's lifestyle among Asian consumers. This will help to spot celebrity misbehaviours to which Asian consumers may be particularly sensitive, and take preventive action either by declining the appointment or by actively managing the media interpretation of such behaviours. In this way, the firm would be equipped to limit potential damage to the brand resulting from the salience or intensification of such behaviours. Further examination of this issue is beyond the scope of this paper, but it hopefully opens interesting avenues for future research.

\subsection{Limitations and Future Research}

The study has several limitations. The first is the small sample size and the sampling method, which may affect the reliability of the data. Second, the association of normative morality with Chinese cultural values requires theoretical and empirical development. In this regard, it would have been helpful to collect information about the individual's collectivist orientation and risk propensity. Such measures should be included in future studies. Third, insofar as the sample for Study 2 was limited to League of Legends' players, its results are only directly relevant to consumers of that or comparable games. More study is needed across different types of games, and also across different types of consumers (e.g., by age and nationality), to draw generalizable conclusions for the online-games industry. Future 
studies ought to include both moral and amoral traits. Studies could also control for the influence of impulsiveness and other personality characteristics of gamers.

Finally, Study 1 did not associate the celebrity with a product or brand and Study 2 did not measure the identification of the consumer with the League of Legends brand. Recent research has begun to integrate both celebrity-endorser traits and brand traits as parts of the study of endorser effectiveness (e.g., Escalas and Bettman 2005; Dwivedi et al. 2014). Thus, future studies should include considerations about identification with specific types of products and brands. Similarly, future studies should include outcomes that go beyond purchase intention, such as brand preference and loyalty, and test the effects of ethical identification in comparative consumption contexts.

\section{References}

Aaker, J.L. 1997. “Dimensions of brand personality." Journal of Marketing Research 34(3): 347-356.

Anderson, C.A., and K.E. Dill. 2000. "Video games and aggressive thoughts, feelings, and behaviour in the laboratory and in life." Journal of Personality and Social Psychology 78: 772-790.

Anderson, C.A., D.A. Gentile, and K.E. Buckley. 2007. Violent video game effects on children and adolescents: Theory, research, and public policy. New York, NY: Oxford University Press. 
Anderson, C.A., A. Shibuya, N. Ihori, E.L Swing, B.J. Bushman, A. Sakamoto, and M. Saleem. 2010. "Violent video game effects on aggression, empathy, and prosocial behavior in Eastern and Western countries." Psychological Bulletin 136: 151-173.

Aquino, K., D. Freeman, A. Reed, W. Felps, V.K. and Lim. 2009. "Testing a Social-Cognitive Model of Moral Behavior: The Interactive Influence of Situations and Moral Identity Centrality." Journal of Personality and Social Psychology 97(1): 123-141.

Aquino, K., and A. Reed. 2002. "The Self-Importance of Moral Identity." Journal of Personality and Social Psychology 83(6): 1423-1440.

Arora, R. 2005. “China's 'Gen Y’ Bucks Tradition: Youngest Chinese Reject Confucian Work Ethic, Embrace West." The Gallup Poll Tuesday Briefing, 19 April. Accessed 7 July, 2016. www.gallup.com/poll/15934/Chinas-Gen-Bucks-Tradition.aspx.

Bartholow, B.D., B.J. Bushman, M.A. and Sestir. 2005. “Chronic violent video game exposure and desensitization to violence: Behavioral and event-related brain potential data." Journal of Experimental Social Psychology 42: 283-290.

Bearden, W.O., and M.J. Etzel. 1982. "Reference group influence on product and brand purchase." Journal of Consumer Research 9(2): 183-194.

Bednall, D.H.B., and A. Collings. 2000. "Effect of Public Disgrace on Celebrity Endorser Value." Australasian Marketing Journal 8(2): 47-57.

Blasi, A. 1984. "Moral identity: Its role in moral functioning." In Morality, Moral Behavior and Moral Development, edited by W. Kurtines and J. Gewirtz, 128-139. NJ: John Wiley and Sons. 
Bushman, B.J., and C.A. Anderson. 2009. "Comfortably numb: Desensitizing effects of violent media on helping others." Psychological Science 20: 273-277.

Carrigan, M., and A. Attalla. 2001. "The myth of the ethical consumer-do ethics matter in purchase behaviour?" Journal of Consumer Marketing 18(7): 560-577.

Chan, K. 2008. "Use of Celebrity in Television Commercials of Youth Products." Working Paper. Hong Kong Baptist University.

Chan, P.A., and T. Rabinowitz. 2006. "A cross-sectional analysis of video games and attention deficit hyperactivity disorder symptoms in adolescents." Annals of General Psychiatry 5: 16-16.

Choi, S.M., W. Lee, and H. Kim. 2005. "Lessons from the Rich and Famous: A Cross-Cultural Comparison of Celebrity Endorsement in Advertising." Journal of Advertising 34: 85-98.

Choi, W.J., and K.P. Winterich. 2013. "Can Brands Move In from the Outside? How Moral Identity Enhances Out-Group Brand Attitudes." Journal of Marketing 77(2): 96-111.

Chu, S., and J. Lin. 2012. “Do Chinese Consumers Care About Corporate Social Responsibility?" Asian Journal of Business Research 2(1): 69-91.

Chung, K.Y., J.W. Eichenseher, and T.T. Taniguchi. 2008. “Ethical perceptions of business students: Differences between East Asia and the USA and among 'Confucian' cultures." Journal of Business Ethics 79: 121-132.

Creyer, E.H., and W.T. Ross. 1997. "The influence of firm behavior on purchase intention: do consumers really care about business ethics?" Journal of Consumer Marketing 14 (6): $421-433$. 
Cuneo, A.Z. 2004. “Marketers Game for Action." Advertising Age 75 (3): 6-6.

Davies, G., R. Chun, R.V. Silva, and S. Roper. 2004. “A Corporate Character Scale to Assess Employee and Customer Views of Organization Reputation." Corporate Reputation Review 7(2):125-146.

Dean, D.H., and A. Biswas. 2001. "Third-party organization endorsement of products: an advertising cue affecting consumer prepurchase evaluation of goods and services." Journal of Advertising 30(4): 41-57.

De Mooij, M.K. 2005. Global Marketing and Advertising: Understanding Cultural Paradoxes. London: Sage.

Dwivedi, A., R.E. McDonald, and L.W. Johnson. 2014. "The impact of a celebrity endorser's credibility on consumer self-brand connection and brand evaluation." Journal of Brand Management 21: 559-578.

Eckhardt, G.M., R. Belk, and T.M. Devinney. 2010. “Why don't consumers consume ethically?" Journal of Consumer Behaviour 9: 426-436.

Erdogan, B.Z. 1999. "Celebrity Endorsement: A Literature Review." Journal of Marketing 15 (4): 291-314.

Erikson, E.H. (1964) Insight and responsibility. New York: Norton.

Escalas, J.E. 2004. "Narrative processing: Building consumer connections to brands." Journal of Consumer Psychology 14(1/2):168-180.

Escalas, J.E., and J.R. Bettman. 2005. "Self-Construal, Reference Groups, and Brand Meaning." Journal of Consumer Research 32: 378-89. 
ESPN. 2015. "League of Legends Prodigy Faker Carries Country on His Shoulders." Accessed July 30, 2016. http://espn.go.com/espn/feature/story/_/id/13035450/league-legendsprodigy-faker-carries-country-shoulders

Friedman, H.H., and L. Friedman. 1979. "Endorser effectiveness by product type." Journal of Advertising Research 19 (5): 63-71.

Gentile, D.A. 2009. "Pathological video game use among youth 8 to 18: A national study." Psychological Science 20: 594-602.

Gentile, D.A. 2011. "The multiple dimensions of video game effects." Child Development Perspectives 5: 75-81.

Gentile, D.A., C.A. Anderson, K. Suzuki, E. Swing, K. Ming Lim, Y. Horiuchi, M. Jelic, B. Krahé, W. Liuqing, A.K. Liau, A. Khoo, P.D. Petrescu, A. Sakamoto, S. Tajima, R.A. Toma, W. Warburton, X. Zhang, and B.C.P. Lam. 2013. “Long-Term Relations Among ProsocialMedia Use, Empathy, and Prosocial Behavior." Psychological Science 25 (1): 358 - 368.

Gilligan, C. 1982. In a Different Voice. Cambridge, MA: Harvard University Press.

Greene, J., and J. Haidt. 2002. "How (and where) does moral judgement work?" Trends in Cognitive Sciences 6(12): 517-523.

Gu, F.F., K. Hung and D.K. Tse. 2008. "When Does Guanxi Matter: Issues of Capitalization and its Dark Sides." Journal of Marketing 72 (4): 12-28.

Hastings, E.C., T.L. Karas, A. Winsler, E. Way, A. Madigan, and S. Tyler. 2009. "Young children's video/computer game use: Relations with school performance and behavior." Issues in Mental Health Nursing 30: 638-649. 
Highscalability. 2014. "How League of Legends Scaled Chat to 70 Million Players." Accessed July 30, 2016. http://highscalability.com/blog/2014/10/13/how-league-of-legendsscaled-chat-to-70-million-players-it-t.html

Horton, D., and R.R. Wohl. 1956. “Mass communication and para-social interaction" Psychiatry 19: 215-229.

Hung, K., K.W. Chan, and C. Tse. 2011. "Assessing celebrity Endorsement effects in China - A Consumer-Celebrity Relational Approach." Journal of Advertising Research 51(4): 608624.

Hung, K., and S.Y. Li. 2007. "The Influence of eWOM on Virtual Consumer Communities: Social Capital, Consumer Learning, and Behavioral Outcomes." Journal of Advertising Research 47: 485-495.

IGN. 2015. "Riot Games Releases Awesome League of Games Infographic." Accessed July 7, 2016. http://www.ign.com/articles/2012/10/15/riot-games-releases-awesome-leagueof-legends-infographic.

Johar, J.S., and M.J. Sirgy. 1991. "Value-expressive versus utilitarian advertising appeals: When and why to use which appeal." Journal of Advertising 20(3): 23-33.

Johnson, A.R. 2005. "When a celebrity is tied to immoral behaviour: Consumer reactions to Michael Jackson and Kobe Bryant." Advances in Consumer Research 32: 100-101.

Kaye, B.K., and T.J. Johnson. 1999. "Research Methodology: Taming the Cyber Frontier Techniques for Improving Online Surveys." Social Science Computer Review 17 (3): 323337 
Keller, K.L. 1993. “Conceptualizing, measuring, and managing customer-based brand equity." Journal of Marketing 57(1): 1-22.

Kelman, H.C. 1961. "Processes of Opinion Change." Public Opinion Quarterly 25: 57-78.

Kim, C.K., D. Han, and S.B. Park. 2001. "The effect of brand personality and brand identification on brand loyalty: Applying the theory of social identification." Japanese Psychological Research 43(4): 195-206.

Kohlberg, L. 1971. "From is to ought: How to commit the naturalistic fallacy and get away with it in the study of moral development." In Cognitive Development and Epistemology, edited by T. Mischel, 164-165. New York: Academic Press.

Lafferty, B.A., R.E. Goldsmith, and S.J. Newell. 2002. "The dual credibility model: The influence of corporate and endorser credibility on attitudes and purchase intentions." Journal of Marketing Theory and Practice 10(3): 1-12.

Langmeyer, L. and M. Walker. 1991. "A first step to identify the meaning in celebrity endorsers", Advances in Consumer Research 18(1): 364-371.

Lee, H-S., and C-H. Cho. 2009. "The matching effect of brand and sporting event personality: Sponsorship implications." Journal of Sport Management 23(1): 41-64.

Liu, M.T., Y. Huang, and J. Minghua. 2007. “Relations among attractiveness of endorsers, match-up, and purchase intention in sport marketing in China." Journal of Consumer Marketing 24(6): 358-365.

Lohneiss, A., and B. Hill. 2014. "The impact of processing athlete transgressions on brand image and purchase intent." European Sport Management Quarterly 14(2): 171-193. 
Louie, T.A., and C. Obermiller. 2002. “Consumer Response to a Firm's Endorser (Dis)Association Decisions." Journal of Advertising 31(4): 41-52.

Louie, T.A., R.L. Kulik, and R. Jacobsen. 2001. "When bad things happen to the endorsers of good products." Marketing Letters 12(1): 13-23.

Lovett, S., L. Simmons, and R.J. Kali. 1999. "Guanxi Versus the Market: Ethics and Efficiency." Journal of International Business Studies 30 (2), 231-247.

McCracken, G. 1989. "Who is the celebrity endorser?: cultural foundations of the endorsement process." Journal of Consumer Research 16(3): 310-21.

MacKinnon, D.P. 2008. Introduction to Statistical Mediation Analysis. NJ: Lawrence Erlbaum Associates.

Malhotra, N.K., and D.F. Birks. 2007. Marketing Research: An Applied Approach. Harlow (England): Financial Times/Prentice Hall.

Miller, F.M., and G.R. Laczniak. 2011. "The Ethics of Celebrity- Athlete Endorsement - What Happens When a Star Steps Out of Bounds?" Journal of Advertising Research 51(3): 499510.

Mishra, A.S., R. Subhadip, and A. Ainsworth. 2015. “Exploring Brand Personality-Celebrity Endorser Personality Congruence in Celebrity Endorsements in the Indian Context." Psychology \& Marketing 32(12): 1158-1174.

Misra, S., and S.E. Beatty. 1990. "Celebrity spokesperson and brand congruence: an assessment of recall and affect." Journal of Business Research 21(2): 159-64. 
Money, R.B., T.A. Shimp, and T. Sakano. 2006. “Celebrity endorsements in Japan and the United States: is negative information all that harmful?" Journal of Advertising Research 46(1): 113-123.

Moon, J., and X. Shen. 2010. "CSR in China research: Salience, focus, and nature." Journal of Business Ethics 94(4): 613-629.

New York Times. 2009. "Phelps is suspended and loses a key sponsor". February 6. Accessed August 8, 2017, http://www.nytimes.com/2009/02/06/sports/06ihtswim.1.19984715.html.

Ohanian, R. 1991. "The impact of celebrity spokespersons' perceived image on intention to purchase." Journal of Advertising Research 31(1): 46-54.

Pham, A. 2003 "Sims Online gives creators a painful reality check" Los Angeles Times, February 4.

Pornpitakpan, C. 2008. “The Effect of Celebrity Endorsers' Perceived Credibility on Product Purchase Intention: The Case of Singaporeans." Journal of International Consumer Marketing 16(2): 55-74.

Sestir, M.A., and B.D. Bartholow. 2010. "Violent and nonviolent video games produce opposing effects on aggressive and prosocial outcomes." Journal of Experimental Social Psychology 46: 934-942.

Sharif, I., and J.D. Sargent. 2006. "Association between television, movie, and video game exposure and school performance." Pediatrics 118: e1061-e1070.

Silvera, D.H., and B. Austad. 2004. "Factors predicting the effectiveness of celebrity endorsement advertisements." European Journal of Marketing 38(11/12): 1509-1526. 
Shrout, P.E., and N. Bolger. 2002. "Mediation in experimental and nonexperimental studies: New procedures and recommendations." Psychological Methods 7(4): 422-445.

Spry, A., R. Pappu, and T.B. Cornwell. 2009. "Celebrity endorsement, brand credibility and brand equity." European Journal of Marketing 45(6): 882-909.

Stanat, M. 2006. China's Generation Y: Understanding the Future Leaders of the World's Next Superpower. Paramus, N.J: Homa \& Sekey.

Tan, D., and R.S Snell. 2002. "The third eye: Exploring Guanxi and relational morality in the workplace." Journal of Business Ethics 41(4): 361-384.

The Star 2014. “Justin Bieber and tennis, anyone?” Accessed May 7, 2014. https://www.thestar.com/news/gta/2014/01/22/justin_bieber_and_tennis_anyone.ht $\mathrm{ml}$.

Thomson, M. 2006. “Human brands: Investigating antecedents to consumers' strong attachments to celebrities." Journal of Marketing 70: 104-19.

Thwaites, D., B. Lowe, L.L. Monkhouse, and B.R. Barnes. 2012. "The Impact of Negative Publicity on Celebrity Ad Endorsements." Psychology and Marketing 29(9): 663-673.

Till, B.D., and T.A. Shimp. 1998. "Endorsers in advertising: The case of negative celebrity information." Journal of Advertising 27: 67-82.

Till, B.D., S.M. Stanley, and M. Busler. 2000. "The match-up hypothesis: Physical attractiveness, expertise, and the role of fit on brand attitude, purchase intent and brand beliefs." Journal of Advertising 29: 1-13. 
Till, B.D., S.M. Stanley, and R. Priluck. 2008. “Classical Conditioning and Celebrity Endorsers: An Examination of Belongingness and Resistance to Extinction." Psychology and Marketing 25(2): 179-196.

TMZ. 2014. "Adidas standing by Bieber". Accessed 7 May, 2016.

http://www.tmz.com/2014/01/23/justin-bieber-adidas-support-endorsement-dealshoes-arrest.

Tripp, C., T.D. Jensen, and L. Carlson. 1994. "The effects of multiple product endorsements by celebrities on consumers' attitudes and intentions." Journal of Consumer Research 20 (4): 535-547.

Vice.com. 2013. "Shock News: Chinese Teenagers Are Obsessed with Justin Bieber, Too". Accessed June 14, 2017, https://www.vice.com/en_uk/article/justin-bieber-fansshanghai-believe-tour-china.

Vranica, S., and M. Futterman. 2009. “Phelps Loses Endorsement Pact, Faces Suspension Over Photos". Wall Street Journal, February 6, 2009.

White, D.W., L. Goddard, and N. Wilbur. 2009. "The effect of negative information transference in the celebrity endorsement relationship." International Journal of Retail and Distribution Management 37: 322-335.

Winterich, K.P., V. Mittal, and K. Aquino. 2013. "When Does Recognition increase Charitable Behavior? Toward a moral Identity-Based model." Journal of Marketing 77: 121-134.

Zhou, L., and P.A. Whitla. 2013. "How negative celebrity publicity influences consumer attitudes: The mediating role of moral reputation." Journal of Business Research 66: 1013-1020. 
Zu, L., and L. Song. 2009. "Determinants of managerial values on corporate social responsibility: Evidence from China." Journal of Business Ethics 88: 105-117. 


\section{Author profiles}

Felix Martin is a lecturer in Marketing at the University of Lancaster (UK), which he joined after completing his PhD at Manchester Business School (UK). His research interests include ethical perception and behaviour in marketing, both in B2B and B2C contexts. Felix Martin has published in The Journal of Business Ethics and has contributed to a number of books from leading publishers in the area of social responsibility and branding. Prior to this, Felix Martin worked as a senior executive for a leading American corporation and read Law at the University of Oxford.

Fu Tao-Peng received her B.A. in Economics at the National Cheng Kung University in Taiwan and her MSc in Marketing with merit at Manchester Business School. She currently works as a marketing executive in a leading marketing agency in Taiwan. This paper reflects some of the findings from her MsC dissertation. 
Fig 1: Conceptual Model

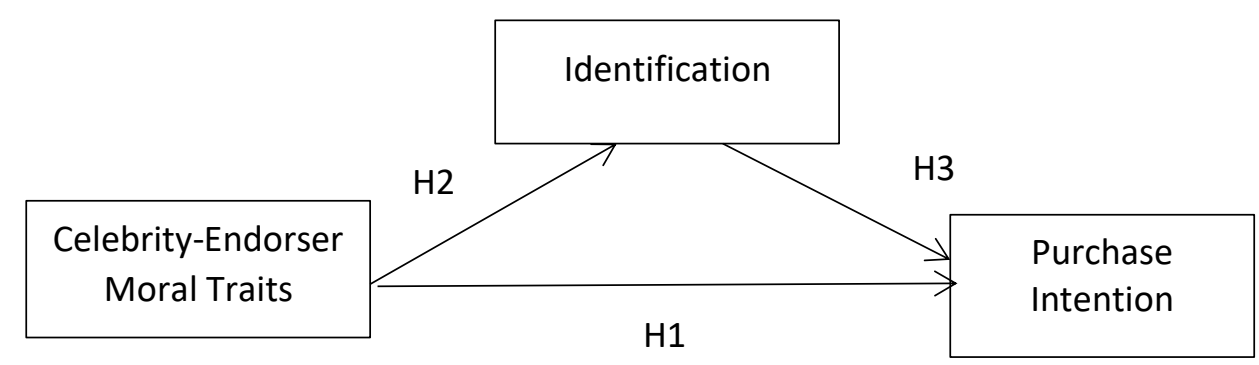


Table 1: Correlations

\begin{tabular}{|l|l|l|l|}
\hline \multicolumn{3}{|c|}{ Study 1 (N=171) [Study 2 (N=90)] } \\
\hline & MT & ID & PI \\
\hline Celebrity-Endorser Moral Traits (MT) & $1[1]$ & $.777^{* *}\left[.596^{* *}\right]$ & $.764^{* *}[0.84]$ \\
\hline Identification (ID) & $.777^{* *}\left[.596^{* *}\right]$ & $1[1]$ & $.812^{* *}[-0.08]$ \\
\hline Purchase Intention (PI) & $.764[.084]$ & $.812^{* *}[-.008]$ & $1[1]$ \\
\hline$* *$ Sign. at 0.01 level (2-tailed) & & & \\
\hline
\end{tabular}


Table 2: Coefficients for Study 1

\begin{tabular}{|l|l|}
\hline H1: MT $\rightarrow$ PI & $.304(<.028$, s.e $=.140)$ \\
\hline H2: MT $\rightarrow$ ID & $.918(<.001$, s.e. $=.083)$ \\
\hline H3: ID $\rightarrow$ IP & $.626(<.001$, s.e. $=.130)$ \\
\hline H4: MT $\rightarrow$ ID $\rightarrow$ PI $)$ & $.575(<.001$, s.e. $=.120)$ \\
\hline
\end{tabular}

Celebrity-Endorser Moral Traits (MT); Purchase Intention (PI); Identification (ID) 


\section{APPENDIX 1: Descriptive Statistics}

\section{Celebrity Moral Traits}

T1: Honest

T2: Sincere

T3: Trustworthy

T4: Socially responsible

\section{Identification with celebrity}

ID1: It would make me feel good to be a person like the celebrity.

ID2: Being someone who has the characteristics of the celebrity is an important part of who I am.

ID3: A big part of my emotional well-being is tied up with the celebrity.

ID4: I would be shamed to be a person like the celebrity.

ID5: Being like Bieber is not really important to me.

ID6: Being like Bieber is an important part of my sense of self.

ID7: I strongly desire to have the characteristics of the celebrity.

\section{Purchase intention}

PI1: Would you buy a product if you saw it being sponsored by the celebrity?

PI2: Would you actively seek out a product endorsed by the celebrity in a store?

PI3: I would consider a product endorsed by the celebrity to be my first choice for future purchases.

PI4: I would buy a higher price for the brand endorsed by the celebrity than competitor's products. 
Bieber Study

Descriptive Statistics

\begin{tabular}{|l|r|r|r|r|r|r|r|}
\hline \multirow{2}{*}{} & \multicolumn{1}{|c|}{$\mathrm{N}$} & \multicolumn{1}{c|}{ Mean } & \multicolumn{1}{c|}{ Std. Deviation } & \multicolumn{2}{c|}{ Skewness } & \multicolumn{2}{|c|}{ Kurtosis } \\
\cline { 2 - 8 } & Statistic & \multicolumn{1}{c|}{ Statistic } & \multicolumn{1}{c|}{ Statistic } & Statistic & Std. Error & Statistic & Std. Error \\
\hline T1 & 171 & 2.08 & .976 & .576 & .186 & -.330 & .369 \\
T2 & 171 & 2.10 & 1.004 & .469 & .186 & -.611 & .369 \\
T3 & 171 & 2.06 & 1.022 & .451 & .186 & -.908 & .369 \\
T4 & 171 & 2.04 & 1.119 & .710 & .186 & -.611 & .369 \\
ID1 & 171 & 1.94 & 1.067 & .912 & .186 & .023 & .369 \\
ID2 & 171 & 1.94 & 1.067 & .765 & .186 & -.519 & .369 \\
ID3 & 171 & 1.89 & .973 & .730 & .186 & -.460 & .369 \\
ID4 & 171 & 3.31 & 1.214 & -.236 & .186 & -.818 & .369 \\
ID5 & 171 & 3.70 & 1.247 & -.640 & .186 & -.544 & .369 \\
ID6 & 171 & 2.02 & .997 & .613 & .186 & -.280 & .369 \\
ID7 & 171 & 2.04 & .976 & .506 & .186 & -.674 & .369 \\
PI1 & 171 & 1.99 & .991 & .709 & .186 & -.239 & .369 \\
PI2 & 171 & 1.90 & .992 & .750 & .186 & -.311 & .369 \\
PI3 & 171 & 1.87 & .962 & .824 & .186 & -.204 & .369 \\
PI4 & 171 & 1.67 & .952 & 1.293 & .186 & .912 & .369 \\
Valid N (listwise) & 171 & & & & & & \\
\hline
\end{tabular}

Faker Study

Descriptive Statistics

\begin{tabular}{|l|r|r|r|r|r|r|r|}
\hline \multirow{2}{*}{} & \multicolumn{1}{|c|}{$\mathrm{N}$} & \multicolumn{1}{c|}{ Mean } & \multicolumn{1}{c|}{ Std. Deviation } & \multicolumn{2}{c|}{ Skewness } & \multicolumn{2}{|c|}{ Kurtosis } \\
\cline { 2 - 7 } & Statistic & \multicolumn{1}{c|}{ Statistic } & \multicolumn{1}{c|}{ Statistic } & \multicolumn{1}{c|}{ Statistic } & Std. Error & Statistic & Std. Error \\
\hline T1 & 90 & 3.433 & 1.0499 & -.773 & .254 & .500 & .503 \\
T2 & 90 & 3.489 & 1.1142 & -.570 & .254 & .129 & .503 \\
T3 & 90 & 3.378 & 1.1953 & -.693 & .254 & -.178 & .503 \\
T4 & 90 & 3.322 & 1.1882 & -.449 & .254 & -.305 & .503 \\
ID1 & 90 & 2.844 & 1.1795 & -.069 & .254 & -.460 & .503 \\
ID2 & 90 & 2.522 & 1.1439 & .013 & .254 & -.913 & .503 \\
ID3 & 90 & 2.778 & 1.2250 & .025 & .254 & -.959 & .503 \\
ID4 & 90 & 2.544 & 1.2909 & .396 & .254 & -.846 & .503 \\
ID5 & 90 & 3.211 & 1.1167 & -.529 & .254 & -.172 & .503 \\
ID6 & 90 & 3.044 & 1.2534 & -.226 & .254 & -.760 & .503 \\
ID7 & 90 & 3.100 & 1.0499 & -.383 & .254 & -.250 & .503 \\
PI1 & 90 & 3.256 & 1.3621 & -.287 & .254 & -1.042 & .503 \\
PI2 & 90 & 2.878 & 1.1301 & -.280 & .254 & -.601 & .503 \\
PI3 & 90 & 3.267 & 1.2790 & -.320 & .254 & -.699 & .503 \\
PI4 & 90 & 3.011 & 1.1465 & -.159 & .254 & -.531 & .503 \\
Valid N (listwise) & 90 & & & & & \\
\hline
\end{tabular}

